Vom Strom der Sprache 
Herta Schwarz

\section{VOM STROM DER SPRACHE}

Schreibart und `Tonart` in Hölderlins Donau-Hymnen

Verlag J. B. Metzler

Stuttgart - Weimar 
Die Deutsche Bibliothek - CIP-Einheitsaufnahme

Schwarz, Herta:

Vom Strom der Sprache : Schreibart und ,Tonart' in Hölderlins

Donau-Hymnen / Herta Schwarz. - Stuttgart : Metzler, 1994

ISBN 978-3-476-00992-0

ISBN 978-3-476-03525-7 (eBook)

DOI 10.1007/978-3-476-03525-7

Dieses Werk einschließlich aller seiner Teile ist urheberrechtlich geschützt. Jede Verwertung außerhalb der engen Grenzen des Urheberrechtsgesetzes ist ohne Zustimmung des Verlages unzulässig und strafbar. Das gilt insbesondere für Vervielfailtigungen, Übersetzungen, Mikroverfilmungen und die Einspeicherung und Verarbeitung in elektronischen Systemen.

(C) 1994 Springer-Verlag GmbH Deutschland

Ursprünglich erschienen bei J. B. Metzlersche Verlagsbuchhandlung und Carl Ernst Poeschel Verlag GmbH in Stuttgart 1994 
Die Sprache ist ein großer Überfluß

(FA 11, S.729) 
Die vorliegende Publikation ist die geringfügig überarbeitete Fassung einer Untersuchung, die im Jahre 1992 abgeschlossen und vom Fachbereich Germanistik der Freien Universität Berlin als Dissertation angenommen wurde. 
1. Einleitung .................... 9

1.1 Gegenstand und Methode . . . . . . . . . . . . . . 9

1.2 Entstehungsgeschichte und Edition der untersuchten Gedichte . . . . . . . . . . . . . . . 14

1.3 Der Aufbau der Arbeit $\ldots \ldots \ldots \ldots$

2. Gedichttexte . . . . . . . . . . . . . . . . . . . . 19

3. Gedichtanalysen . . . . . . . . . . . . . . . . 24

3.1 „Am Quell der Donau“ . . . . . . . . . . . . . . . 24

3.1.1 Grammatische Analyse nach Wortarten . . . . . . . . . . 24

3.1.2 Struktur der Strophen . . . . . . . . . . . . . . 61

3.2 „Jezt komme, Feuer" . . . . . . . . . . . . . . . . . 82

3.2.1 Grammatische Analyse nach Wortarten _. . . . . . . . . 82

3.2.2 Struktur der Strophen . . . . . . . . . . . . . . . 111

3.3 Die Dynamik in der Konstruktion der Hymnen . . . . . . . 127

3.3.1 „Am Quell der Donau“ . . . . . . . . . . . . . . . . . . 127

3.3 .2 „Jezt komme, Feuer" . . . . . . . . . . . . . . . . . . . 134

3.3 .3 Vergleich . . . . . . . . . . . . . . . 137

4. Hölderlins poetische Theorie und deren Applizierbarkeit auf die Donau-Gedichte . . . . . . . . . . . . . . . 142

4.1 Rekurs auf die Rhein-Hymne: Das, Gesetz des Gesangs' . . . . 142

4.2 Die „Töne“: „Kunstkarakter" und „Grundstimmung“ . . . . 148

4.3 Analyse des Gedichts „Am Quell der Donau“ nach der Theorie vom, Wechsel der Töné. . . . . . . . . . . . . . . 155

4.4 Analyse des Gedichts "Jezt komme, Feuer" nach der Theorie vom, Wechsel der Töne‘. . . . . . . . . . . . . . . . 176

5. Abschließende Bemerkungen und Ausblick . . . . . . . . . 198 Literaturverzeichnis . . . . . . . . . . . . . . . . . 204 